\title{
Profile of urinary dapsone /creatinine ratios after oral dosage with dapsone
}

\author{
GORDON A. ELLARD \\ MRC Unit for Laboratory Studies of Tuberculosis, \\ Royal Postgraduate Medical School, Ducane Road, \\ London, W12 OHS
}

Received for publication 24 March 1980

\begin{abstract}
Summary The ratios of the concentration of DDS plus its diazotisable metabolites to creatinine (D/C ratios) of successive urine samples collected after the ingestion of either single or consecutive daily doses of $100 \mathrm{mg}$ DDS followed a pattern that was closely in accord with the hypothesis that once absorption is complete the rate of elimination of DDS and its diazotisable metabolites falls exponentially at a rate similar to the decline in plasma DDS concentrations. Diuresis influenced $\mathrm{D} / \mathrm{C}$ ratios to only a minor extent. The results obtained indicated the validity determining dapsone compliance by determining $\mathrm{D} / \mathrm{C}$ ratios of urine samples from either the individual patient or a group of patients self-administering their prescribed daily DDS medication, provided that the results obtained are compared with those achieved with fully supervised treatment.
\end{abstract}

\section{Introduction}

In 1974 my colleagues and I described a quantitative urine-test method for assessing the regularity with which leprosy patients self-administer their prescribed daily doses of dapsone (DDS). ${ }^{1,2}$ In this method the ratio of the concentration of DDS plus its diazotisable metabolites to creatinine in the urine is determined using simple colorimetric methods (' $D / C$ ratio') and the $\mathrm{D} / \mathrm{C}$ ratios of urine samples collected from out-patients self-administering their DDS treatment compared with those from in-patient controls given the same daily dose of DDS under strict supervision. We first used this method to investigate the regularity with which out-patients in Malawi ingested their prescribed treatment ${ }^{2}$ and it has subsequently been used by other investigators to monitor dapsone compliance among patients in Ethiopia, ${ }^{3}$ Tanzania, ${ }^{4}$ India, ${ }^{5-7}$ Kenya $^{8}$ and Burma. ${ }^{9}$ Our method has however recently been criticized by Hagan and Smith ${ }^{10}$ who described an investigation that appeared 
to indicate that the intra-individual variation in the $\mathrm{D} / \mathrm{C}$ ratios of consecutive urine samples voided between repeated daily DDS doses may be so large and unpredictable as to make the determination of $\mathrm{D} / \mathrm{C}$ ratios on single urine samples an unreliable measure of the compliance of individual patients. They also proposed an alternative modification of the Bratton Marshall procedure ${ }^{11}$ for estimating DDS plus its metabolites that they claimed was more reproducible and likely to give lower "blank" values from urine samples from untreated controls than the modification ${ }^{1}$ that we employed.

This report describes an investigation of the change with time in the magnitude of the $\mathrm{D} / \mathrm{C}$ ratios of consecutive urine samples collected after the ingestion of single or repeated daily doses of DDS, and a comparison of the results obtained by the two modifications of the Bratton and Marshall procedure for determining DDS plus its metabolites.

\section{Methods}

\section{Urine collections}

The 10 healthy male adult volunteers who participated in these studies did so after giving informed consent. Subject A (the author) ingested consecutive daily doses of 50 and $25 \mathrm{mg}$ DDS in Study I, single $100 \mathrm{mg}$ doses of DDS in Studies II-IV, 6 consecutive daily doses of $100 \mathrm{mg}$ DDS in Study V and 5 consecutive daily doses of $100 \mathrm{mg}$ DDS in Study VI. The other 9 volunteers swallowed single $100 \mathrm{mg}$ doses of DDS in Study IV. In order to ensure that traces of DDS or its metabolites were not carried over from one investigation to the next, each study was separated by an interval of at least a month. In Studies II-VI, the DDS doses were taken with a glass of water approximately $2 \mathrm{~h}$ after a light breakfast and $3 \mathrm{hr}$ before lunch after first obtaining a pretreatment urine collection.

In Study I complete urine collections were made from $0-2,2-4,4-6$, $6-8,8-10,10-16$ and $16-24 \mathrm{~h}$ on the day prior to the first DDS dose and after each of the two doses. In the second study urine collections were made at hourly intervals up to $4 \mathrm{~h}$, at 2-hourly intervals from $4-12 \mathrm{~h}$ and at 12 hourly intervals from 12-96 h. In Study III urine collections were made at hourly intervals up to $4 \mathrm{~h}$, at 2-hourly intervals from $4-16 \mathrm{~h}$, from $16-23,23-25$ and $25-35 \mathrm{~h}$, and thereafter at alternating 2- and 10-hourly intervals up to $169 \mathrm{~h}$. In the fourth study complete urine collections were made from $0-2,2-4$, and 4-6 h, and hourly collections were then obtained at $1,2,5,6,7,8,9$ and 14 days (i.e. from $23.5-24.5$ h, $47.5-48.5$ h, $119.5-120.5$ h, etc.). In Study V hourly urine collections were made immediately before and after ingestion of the final DDS dose, and 2-hourly collections were then obtained from 1-11 h and at daily intervals up to 7 days (i.e. from $23-25 \mathrm{~h}, 47-49 \mathrm{~h}$, etc.). In the 
sixth study complete urine collections were made at 2-hourly intervals up to $8 \mathrm{~h}$, from $8-20 \mathrm{~h}$ and then from $20-22 \mathrm{~h}$ and $22-24 \mathrm{~h}$ after the ingestion of each successive daily DDS dose. After measuring the volumes of the urine collections, samples were stored at $-20 \mathrm{C}$ prior to analysis.

\section{Analytical methods}

In Study I urinary concentrations of diazotisable compounds (as DDS equivalents) were determined using both Hagan and Smith's ${ }^{10}$ and our ${ }^{1}$ modification of the Bratton and Marshall procedure. Thereafter only the latter modification was employed. Creatinine concentrations were estimated using an adaptation of the alkaline picrate method. ${ }^{1}$

\section{Results and Discussion}

\section{Comparison of Hagan and Smith's and our modification of the Bratton and} Marshall procedure for the determination of DDS and its metabolites

Duplicate estimations were made using both modifications of the Bratton and Marshall procedure of the concentrations of diazotisable compounds in the 7 pre-treatment and 14 post-treatment urine samples collected in Study I. The concentrations of diazotisable compounds in the pre-treatment samples determined using Hagan and Smith's modification were consistantly about 50\% higher than those estimated by our procedure, mean pre-treatment $\mathrm{D} / \mathrm{C}$ ratios averaging $4.4 \pm 0.7 \mu \mathrm{g} / \mathrm{mg}$ as compared with $2.9 \pm 0.3 \mu \mathrm{g} / \mathrm{mg}$ by our method. Despite their anticipation to the contrary, the increased 'blank' values obtained by Hagan and Smith procedure can readily be understood since in their method samples are acid-hydrolysed by boiling for $15 \mathrm{~min}$ prior to reaction, a step that could well result in the liberation of significant amounts of endogenous diazotisable amines.

There was however an extremely close correlation between the concentrations of DDS plus its metabolites determined among the post-treatment samples by the two modifications $(r=0.96)$, although Hagan and Smith's alternative gave slightly lower values $(86 \%)$ than ours. The precision of both methods was excellent, duplicate errors averaging about $\pm 1.2 \%$. Although in our modification of the Bratton and Marshall procedure ${ }^{1}$ the azo dye formed from DDS settles out as an extremely fine precipitate after standing for $30-60 \mathrm{~min}$, contrary to the experience of Hagan and Smith, ${ }^{10}$ we have never found that this led to inaccuracies in the measurement of optical densities $5 \mathrm{~min}$ after the addition of the $\mathrm{N}$-naphthyl-ethylene-diamine reagent. It was therefore concluded that Hagan and Smith's modification of the Bratton and Marshall procedure for determining DDS and its metabolites is no more 
reproducible, and probably less specific than the simpler procedure that we originally described.

\section{Time profile of urinary $D / C$ ratios after the ingestion of single doses of DDS}

The results obtained after the ingestion of single doses of $50 \mathrm{mg}$ and $100 \mathrm{mg}$ DDS (Studies I-IV) are summarised in. Table 1 and the data from the most extensive investigation (Study. III) illustrated in Fig. 1. Urinary D/C ratios

Table 1. D/C ratios after the taking of single or multiple daily doses of DDS (Subject A)

\begin{tabular}{ccccccc}
\hline Dose DDS & $\begin{array}{c}\text { No. } \\
\text { doses }\end{array}$ & $\begin{array}{c}\text { Peak } \\
\text { D/C ratio* } \\
(\mu \mathrm{g} / \mathrm{mg})\end{array}$ & $\begin{array}{c}\text { Duration of } \\
>90 \% \text { Peak } \\
(\mathrm{h})\end{array}$ & $\begin{array}{c}\text { Pretreatment } \\
\mathrm{D} / \mathrm{C} \text { ratio } \\
(\mu \mathrm{g} / \mathrm{mg})\end{array}$ & $\begin{array}{c}\text { Asymptotic** } \\
\text { D/C ratio } \\
(\mu \mathrm{g} / \mathrm{mg})\end{array}$ & $\begin{array}{c}\text { Half-life** } \\
(\mathrm{h})\end{array}$ \\
\hline 50 & 1 & 29 & $2-6$ & 2.9 & - & - \\
100 & 1 & 54 & $1-8$ & 4.8 & 3.6 & 24 \\
100 & 1 & 60 & $3-8$ & 3.6 & 4.4 & 23 \\
100 & 1 & 52 & $2-4$ & 3.0 & 3.7 & 24 \\
100 & 6 & 93 & $1-7$ & $56^{\dagger}$ & $4.8 \ddagger$ & 29 \\
100 & 5 & 97 & $0-2$ & $60^{\dagger}$ & - & - \\
\hline
\end{tabular}

${ }^{*}$ Ratio DDS equivalents/creatinine

**Estimated using an iterative procedure (see text).

†rior to final DDS dose

$¥$ After final DDS dose

reached near maximal values after $1-2 \mathrm{~h}$ and, after allowing for pretreatment blank values that averaged $3.7 \mu \mathrm{g} / \mathrm{mg}$, peak ratios were approximately proportional to dosage. From $8 \mathrm{~h}$, when it was assumed that absorption of the drug must have been complete, $\mathrm{D} / \mathrm{C}$ ratios of successive urine collections were closely similar (Fig. 1) to those calculated on the assumption that they could be represented by the sum of 2 components, one due to the elimination of DDS plus its diazotisable metabolites that fell exponentially with time, and the other representing natural diazotisable compounds whose magnitude did not change with time ('asymptotic' $\mathrm{D} / \mathrm{C}$ ratio). An iterative computer program was used to calculate the best fitting curve to the observed data illustrated in Fig. 1. The decline in the rate of elimination of DDS plus its diazotisable metabolites was equivalent to a half-life of $24 \mathrm{~h}$. Such a half-life was identical to that estimated for the urinary elimination of DDS plus its N-glucuronide after giving a further $100 \mathrm{mg}$ dose of DDS (Study IV) and using a sensitive and specific high-pressure liquid chromatographic method to determine DDS plus acid-labile DDS. ${ }^{12}$ Similar estimates of the half-life for the urinary elimination of DDS and its diazotisable metabolites and the asymptotic $\mathrm{D} / \mathrm{C}$ ratio were obtained when the $\mathrm{D} / \mathrm{C}$ ratios of consecutive urine samples collected after the ingestion of the other 2 single doses of $100 \mathrm{mg}$ DDS (Studies II and IV) were analysed by the iterative computer program. (Table 1). 


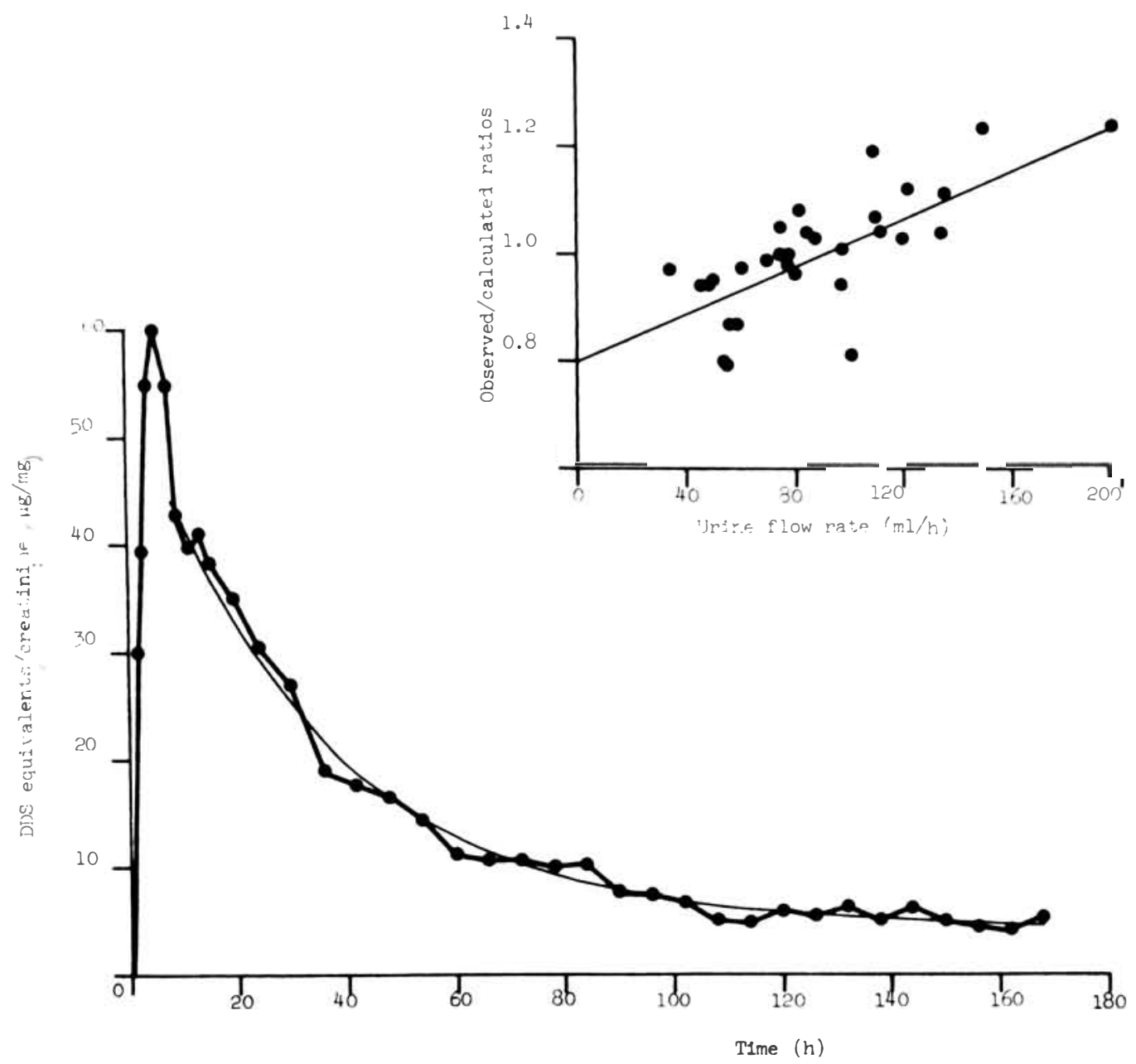

Figure 1. Time profile of urinary $\mathrm{D} / \mathrm{C}$ ratios after the ingestion of a single dose of $100 \mathrm{mg}$ DDS. Points represent the observed ratios, while the calculated ratios are shown as the smooth fine line. The insert shows the correlation between observed/calculated $\mathrm{D} / \mathrm{C}$ ratios and urine flow rate.

Even though the average absolute difference between the individual observed and calculated $\mathrm{D} / \mathrm{C}$ ratios after giving the second $100 \mathrm{mg}$ DDS dose was only $8 \%$ (Fig. 1), there was a close correlation $(r=0.73, p \ll 0.001)$ between the ratios of observed to calculated values and urine flow rates (insert Fig. 1). This indicates that measuring $\mathrm{D} / \mathrm{C}$ ratios does not compensate perfectly for the effect of diuresis on the exretion of DDS and its metabolites. Nevertheless the effect of urine flow on $\mathrm{D} / \mathrm{C}$ ratios is small since it was estimated that an increase in urinary excretion from 30 to $120 \mathrm{ml} / \mathrm{h}$ would only result in $\mathrm{D} / \mathrm{C}$ ratios increasing by about $25 \%$. 
The $\mathrm{D} / \mathrm{C}$ ratios of the urine samples collected from the 10 volunteers pretreatment and at varying times after the ingestion of single $100 \mathrm{mg}$ doses of DDS (Study IV) are summarised in Table 2. In every case peak $\mathrm{D} / \mathrm{C}$ ratios were

Table 2. D/C ratios after the taking of single doses of $100 \mathrm{mg}$ DDS (10 subjects)

\begin{tabular}{rccc}
\hline $\begin{array}{c}\text { Time } \\
(\mathrm{h})\end{array}$ & $\begin{array}{c}\text { D/C ratios* } \\
(\mu \mathrm{g} / \mathrm{mg})\end{array}$ & $\begin{array}{c}\text { Time } \\
(\text { days })\end{array}$ & $\begin{array}{c}\mathrm{D} / \mathrm{C} \text { ratios } \\
(\mu \mathrm{g} / \mathrm{mg})\end{array}$ \\
\hline 0 & $3.0(1.9-4.4)^{* *}$ & 5 & $4.4(3.1-6.7)$ \\
1 & $23.6(9.1-41.8)$ & 6 & $3.9(2.6-5.1)$ \\
3 & $45.2(28.2-70.7)$ & 7 & $3.6(2.2-6.3)$ \\
5 & $39.2(25.0-54.8)$ & 8 & $3.4(2.0-4.9)$ \\
24 & $21.7(15.1-26.9)$ & 9 & $3.0(1.4-4.1)$ \\
48 & $11.1(6.6-15.8)$ & 14 & $3.1(1.7-4.0)$ \\
& * Ratio DDS equivalents/creatinine & & \\
\hline
\end{tabular}

encountered at $3 \mathrm{~h}(2-4 \mathrm{~h}$ urine collections). Thereafter the $\mathrm{D} / \mathrm{C}$ ratios steadily decreased until by 9 days they had reached pre-treatment values. From 24 to $48 \mathrm{~h}$ the component due to DDS and its metabolites declined on average at a rate equivalent to a half-life of $20 \mathrm{~h}$, which is similar to a value of $23 \mathrm{~h}$ that may be calculated from the data set out in Table 2 of our original paper ${ }^{1}$ for the $\mathrm{D} / \mathrm{C}$ ratios of urine samples collected from Malaysian leprosy patients after the ingestion of a single dose of $200 \mathrm{mg}$ DDS. An analysis of the data obtained from the 10 volunteers investigated in the Study IV indicated that the average absolute difference between the individual observed $\mathrm{D} / \mathrm{C}$ ratios and the values predicted on the assumption that they were equal to the sum of an exponentially falling component plus a constant, probably lay between $11 \%$ and $20 \%$. The similarity in these estimates of the average half-life for the urinary elimination of DDS plus its diazotisable metabolites and those published for the decline in plasma DDS concentrations ${ }^{2,13-17}$ suggests that the rate of urinary excretion of DDS and its diazotisable metabolites in probably directly proportional to the concomitant plasma DDS concentrations.

\section{Pattern of urinary D/C ratios after the ingestion of repeated daily doses of DDS}

After giving 5 or 6 consecutive daily doses of $100 \mathrm{mg}$ DDS (Studies V and VI) peak and trough $\mathrm{D} / \mathrm{C}$ ratios gradually increased to about 95 and $58 \mu \mathrm{g} / \mathrm{mg}$, respectively (Table 1). Such a pattern was to have been anticipated from the previously estimated half-life (about $24 \mathrm{~h}$ ) for the elimination of DDS and its diazotisable metabolites. The results obtained in Study VI demonstrated that the $\mathrm{D} / \mathrm{C}$ ratios of urine samples collected during any one 24-h period after giving successive daily doses of DDS varied over a very limited range (from 
1.3- to 1.7-fold). This finding, coupled with the smooth and expected timepattern of $\mathrm{D} / \mathrm{C}$ ratios after giving a single $100 \mathrm{mg}$ dose of the drug (Fig. 1), is in sharp contradiction to the results described by Hagan and Smith ${ }^{10}$ who reported $\mathrm{D} / \mathrm{C}$ ratios ranging up to 4.5 -fold over a period of 24 -h among patients receiving supervised daily doses of DDS and concluded that the time course of their variation showed no closely predictable pattern. By contrast the findings of the present study support earlier evidence obtained by Low and Pearson ${ }^{4}$ for limited intra-individual variability in $\mathrm{D} / \mathrm{C}$ ratios. Thus an analysis of the data illustrated in Fig. 3 of Low and Pearson's paper indicates that among the 12 Ethiopian patients they studied, the $\mathrm{D} / \mathrm{C}$ ratios of urine samples collected immediately before the next daily supervised dose was swallowed, varied on average by only about $\pm 15 \%$ from day to day. This evidence indicates that reliable information on individual patient compliance may be acquired by comparing the $\mathrm{D} / \mathrm{C}$ ratios of single urine samples collected at either surprise home visits or out-patient clinic attendances with those of control samples obtained after a period of about 5 days supervised daily treatment. The chief limitation to monitoring individual compliance is therefore probably the impracticability of giving the supervised treatment in many situations rather than intra-individual variability in $\mathrm{D} / \mathrm{C}$ ratios.

\section{Acknowledgements}

I am indebted to Mr. V.R. Aber for writing the iterative program to analyse the time profile of the $\mathrm{D} / \mathrm{C}$ ratios and for other statistical help. My thanks are also due to the volunteers for their participation in the investigation.

\section{References}

1 Ellard GA, Gammon PT, Helmy HS, Rees RJW. Urine tests to monitor the selfadministration of dapsone by leprosy patients. Amer J Trop Med Hyg 1974; 23: 464-70.

${ }^{2}$ Ellard GA, Gammon PT, Harris JM. The application of urine tests to monitor the regularity of dapsone self-administration. Lepr Rev 1974; 45: 224-34.

3 Low SJM, Pearson JMH. Do leprosy patients take DDS regularly? Lepr Rev 1974; 45: 218-23.

${ }^{4}$ Huikeshoven HCJ, Honhoff C, Van Eys GJJM, Anten JGF, May JMA, Van Helden HPT. Weekly self-medication of leprosy patients monitored by DDS/creatinine ratios in urines. Lepr Rev 1976; 47: 201-9.

5 Jesudasan K, George B, Chacko CJG, Taylor PM, Kurian PV, Job CK. An evaluation of the self-administration of DDS in Gudiyatham Taluk. Lepr India 1976 (Suppl.); 48: $668-76$.

${ }^{6}$ Naik SS, Ganapati R. Regularity of dapsone intake by leprosy patients attending urban treatment centre. Lepr India 1977; 49: 207-15. 
7 Balakrishnan S. Monitoring self-administration of dapsone by patients. Lepr India 1977; 49: $364-71$.

${ }^{8}$ Huikeshoven H, Bijleveld I. Encouraging results from DDS urine analysis among registered leprosy patients in the Wangas, Kenya: An exception that challenges the rule. Lepr Rev 1978; 49: 47-52.

9 Gyi KM, Lwin MM, Myaing YY, Oo KM, Shwe T. Reliability of dapsone selfadministration by leprosy patients in the Rangoon area. Lepr Rev 1978; 49: 283-6.

10 Hagan KJ, Smith SE. Variability of urinary dapsone/creatinine ratios in leprosy patients fully compliant with dapsone therapy. Lepr Rev 1979; 50: 129-34.

11 Bratton AC, Marshall EK. A new coupling component for sulfanilamide determination. $J$ Biol Chem 1939; 128: 537-50.

12 Jenner PJ, Ellard GA. Unpublished results.

13 Peters JH, Gordon GR, Ghoul DC, Tolentino JG, Walsh GP, Levy L. The disposition of the antileprotic drug dapsone (DDS) in Philippine subjects. Amer J Trop Med Hyg 1972; $21: 450-7$.

14 Gelber RH, Rees RJW. Dapsone metabolism in patients with dapsone-resistant leprosy. Amer J Trop Med Hyg 1975; 24: 963-7.

15 Peters JH, Gordon GR, Karat ABA. Polymorphic acetylation of the antibacterials, sulfamethazine and dapsone in South Indian subjects. Amer J Trop Med Hyg 1975; 24: $641-8$.

16 Peters JH, Murray JF, Gordon GR, Levy L, Russell, DA, Scott GC, Vincin DR, Shepard CC. Acedapsone treatment of leprosy patients: response versus drug disposition. Amer J Trop Med Hyg 1977; 26: 127-36.

17 Peters JH, Gordon GR, Murray JF, Meyers WM. Metabolic disposition of dapsone in African leprosy patients. Lepr Rev 1979; 50: 7-19. 